\title{
Infantile Hemangiomas: A Disease Model in the Study of Vascular Development, Aberrant Vasculogenesis and Angiogenesis
}

\author{
Alvin Wong and June $\mathrm{K}$. Wu \\ Department of Surgery, College of Physicians E Surgeons, \\ New York, NY, \\ USA
}

\section{Introduction}

Infantile hemangiomas (IHs) belong to a family of lesions called vascular anomalies. Vascular anomalies are classified into either vascular tumors or vascular malformations, with the IH being the most common vascular tumor, affecting approximately $5 \%$ of infants (Frieden, Haggstrom et al 2005). Despite their prevalence, the origin and pathogenesis of IHs remains poorly understood.

Clinically, IHs undergo a predictable course of rapid proliferation shortly after birth, followed by stabilization and involution throughout childhood. Occasionally, a fibrofatty residuum results after involution is complete. Despite its predictable clinical course, the regulatory mechanisms throughout different phases are only recently being elucidated (Frieden, Haggstrom et al. 2005).

During the proliferative phase, IH can cause serious morbidity and even mortality. Rapidly proliferating hemangiomas can be dangerous as they have potential to ulcerate and bleed. While disorganized, IHs are high-flow lesions; occasionally, life-threatening bleeding can occur. The location of the IH can also be detrimental. Hemangiomas in the peri-orbital area can cause obstructive amblyopia and astigmatism, and airway hemangiomas can cause stridor and respiratory distress. Visceral hemangiomas of the liver can cause congestive heart failure, hepatomegaly, and anemia; the mortality rate with treatment is significant, up to 30\% (Arneja and Mulliken, 2010; Bitar et al., 2005; Boon et al., 1996; Ceisler \& Blei, 2003; Chamlin et al., 2007; Haggstrom et al., 2006a; Schwartz et al., 2006).

In recent years, PHACE syndrome has been described and characterized. PHACE syndrome comprises a constellation of findings including Posterior fossa anomalies, large facial Hemangioma, Arterial anomalies, Cardiac abnormalities/aortic Coarctation, and Eye anomalies (Frieden et al., 1996). Infants with PHACE syndrome are at increased risk for strokes, neurological and cardiac consequences (Burrows et al., 1998; Drolet et al., 2006).

Another syndrome featuring a large hemangioma over an area with aberrant underlying anatomical structures have also been described. PELVIS syndrome describes Perineal hemangioma, External genitalia malformations, Lipomyelomeningocele, Vesicorenal anomalies, Imperforate anus, and Skin tag (Girard et al., 2006). PHACE and PELVIS syndromes suggest that there may be an association between a cutaneous hemangioma and 
abnormal development of underlying anatomy. Given the existence of these syndromes, as well as the predisposition for hemangiomas to occur at the boundaries of developmental units near lines of fusion between mesenchymal growth plates (Waner et al., 2003), it seems likely that the formation of hemangiomas is closely related to the developmental events that take place during embryogenesis.

There are currently no FDA-approved treatments for IHs, (Acevedo and Cheresh 2008; Frieden et al., 2005) although corticosteroids and propanolol have been used with good control of problematic IHs. Laboratory studies have suggested that corticosteroids affect the vascular endothelial growth factor receptor (VEGFR) pathway (Greenberger et al., 2010), and in vitro studies have shown that propanolol can cause apoptosis in endothelial cells (Lamy et al., 2010). However, despite these laboratory studies, the exact mechanisms of action of these medications on IHs are still unknown. Occasionally, due to either failure of medical treatment or the urgency of the potential morbidity and mortality, an infant will require urgent surgical intervention (Arneja \& Mulliken, 2010; Rabhar et al., 2004).

In summary, despite the prevalence and potential morbidities and mortalities, treatment of IHs relies on pharmacotherapy with poorly understood mechanisms of action, and surgical intervention when necessary. Part of the reason treatment for IHs is hampered is due to poor understanding of pathogenesis and regulatory signals governing its natural history. Therefore, understanding the pathogenesis and regulation of IH growth and involution will allow more directed therapy. Moreover, based on associations in PHACE and PELVIS syndromes the development of IH may be related to other abnormal anatomic developments during embryogenesis. Therefore, IH may be a useful disease model to study vascular development and vasculogenesis, as well as give insight to angiogenesis in pathologic settings.

\section{Clinical course of IH}

IHs typically affect the skin and occur in 4 to $10 \%$ of white infants (Holmdahl et al., 1955), with higher incidence in premature infants with low birth weight (Amir et al., 1986), high maternal age for the first baby, multiple gestation, complicated pregnancies with preeclampsia or placental abnormalities such as placenta previa. A lower rate is observed in dark-skinned children. There is a female predisposition of 3:1 to 5:1. IHs occur most often on the head and neck (60\%), followed by the trunk (25\%) and extremities (15\%). Usually, cutaneous IHs arise as a single lesion; however, up to $20 \%$ of them occur as multiple lesions and are also more likely to involve the viscera. IH can develop in the GI tract, pancreas, kidney, lung, heart, mediastinum, meninges, and brain.

By definition, IHs occur after birth. Often, small telangiectasias or discoloration of the skin resembling a bruise herald the future development of the $\mathrm{IH}$, but the frank lesion is not noticed until several weeks after birth. Congenital hemangiomas are vascular tumors that are fully developed at birth and do not have postnatal growth. They either involute rapidly (Rapidly Involuting Congenital Hemangiomas, RICH), or will not involute (Non-Involuting Congenital Hemangioma, NICH), RICHs and NICHs have a different clinical course from IHs and will not be discussed here.

After their initial appearance, IHs grow quickly over the first 6 to 8 weeks of the infant's life during the proliferative phase. Depending on their location within the dermis, IHs can vary in their appearance. Tumors within the dermis are characterized by a bright red coloration, are raised, and have a bosselated appearance [Figure 1]. 


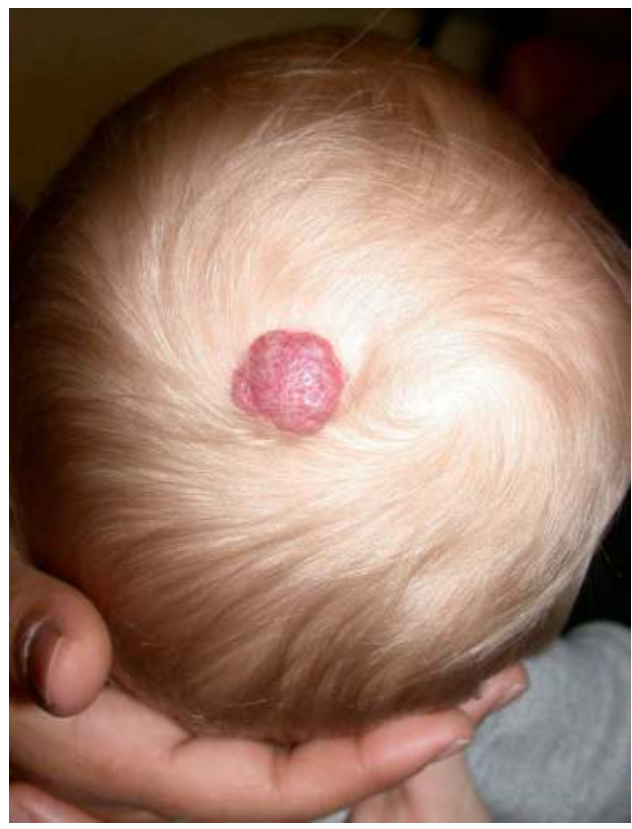

Fig. 1. Proliferating hemangioma of the scalp located in the dermis of an infant. Note the bright red color, elevation above the level of the normal surrounding skin, and raised, bosselated texture.

Those developing beneath the dermis in the subcuticular layer are usually only slightly raised and blue in color [Figure 2]. Growth usually plateaus before a year of age, but there are no reliable predictors for how large an IH can become in the first weeks of life.

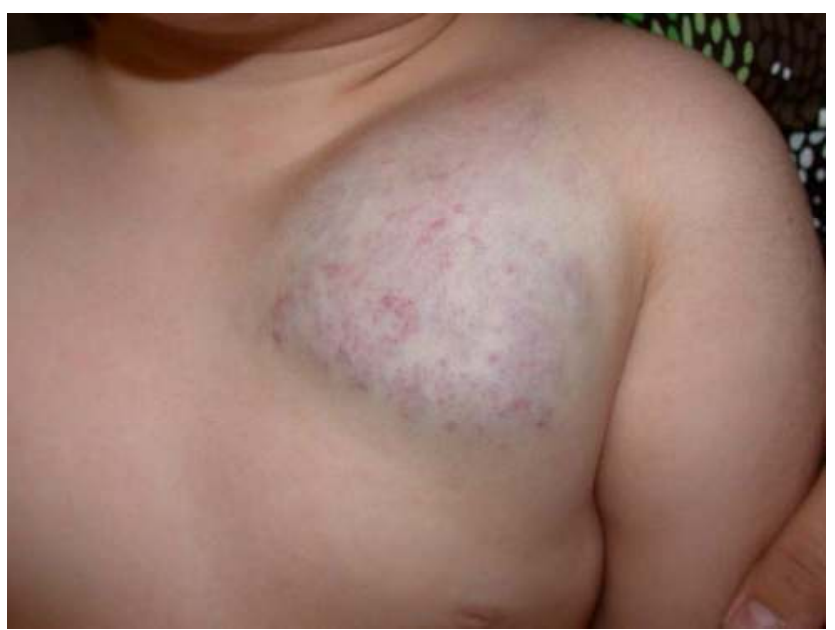

Fig. 2. Proliferating hemangioma located in the subcuticular layer of skin in an infant. Note the blue color, less prominent elevation, and smoother skin texture compared to Fig. 1. 
During the involuting phase, generally from the age of 1 until 5 to 7 years, the IH continues to grow, although more slowly and in proportion with the child. Lesions located in the superficial dermis become less tense by palpation and a dull purple instead of crimson on visual inspection (Mulliken et al., 2000) [Figure 3].

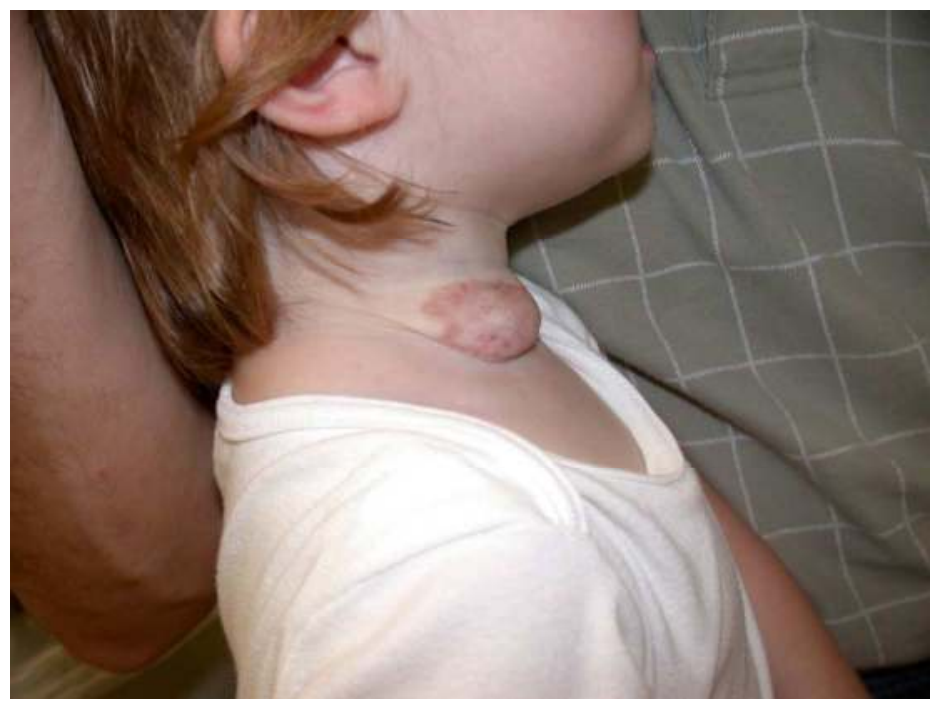

Fig. 3. Involuting hemangioma of the neck in a child. Note the mottled dull red and purple coloring compared to Fig. 1, as well as loose, extraneous skin and smoother texture.

The rate of this regression is difficult to predict, with no apparent links to appearance, location, gender, cutaneous depth, or size. However, involution is usually complete by 5 years of age in $50 \%$ of children, 7 years in $70 \%$, and most by 10 to 12 years (Bowers et al., 1960).

\section{Complications of IH}

The potential morbidity and mortality that can occur as a result of $\mathrm{IH}$ is varied and ranges from life-threatening bleeding, airway obstruction, or threat to the visual axis during proliferation, to scarring and/or disfigurement during and after involution (Maguiness \& Frieden, 2010).

Ulceration during proliferation occurs in 5\% to $13 \%$ of all of $\mathrm{IH}$ and can cause significant morbidity for affected patients as a result of pain and scarring, as well as anxiety for parents [Figure 4].

Periorbital IHs can cause strabismus and amblyopia from the resultant obstruction of vision, and astigmatism can arise from a concomitant pressure or mass effect. If visual compromise is suspected, systemic therapy or surgical debulking is indicated. In patients in which amblyopia has already developed, the unaffected eye is patched (Ceisler \& Blei, 2003; Ceisler et al., 2004; Schwartz et al., 2006).

Other potentially life-threatening complications include airway compromise in subglottic hemangiomas and symptomatic liver hemangiomas. Segmental hemangiomas, especially 


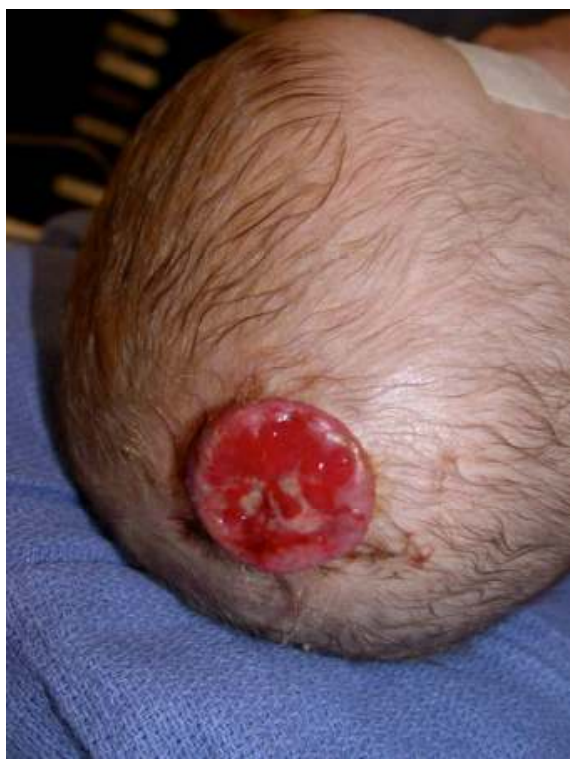

Fig. 4. Ulcerated proliferating hemangioma of the scalp in an infant.

those located in the mandibular region (classically referred to as having a "beard" distribution), have risk up to $63 \%$ of an associated airway hemangioma (Orlow et al., 1997). All patients with "beard distribution" hemangiomas should have an otolaryngologist evalutate him or her by laryngoscopy to rule out an airway hemangioma. Obstructive airway hemangiomas present with biphasic stridor. However, they may not be symptomatic until 6-8 weeks of life, when the airway hemangioma grows to a critical size that obstructs airflow. If the lesions are symptomatic, they may be treated with surgical or laser ablation, with or without systemic pharmacotherapy (Rahbar et al., 2004; Saetti et al., 2008).

Multifocal liver hemangiomas can cause high-output congestive right-sided heart failure, while diffuse liver hemangiomas, which fill the entire liver, can cause abdominal compartment syndrome and severe hypothyroidism with myxedema coma (ChristisonLagay et al., 2007). In these cases, aggressive management of the hypothyroidism is necessary, systemic or surgical therapy may be required, and rarely even a liver transplant is a therapeutic option (Maguiness \& Frieden, 2010).

\section{Associated syndromes}

$\mathrm{IH}$ is also a prominent feature of two syndromes, PHACES and PELVIS. PHACES is a rare neurocutaneous syndrome that can include a constellation of problems such as Posterior fossa malformations, Hemangiomas, Arterial anomalies, Coarctation of the aorta and cardiac defects, Eye abnormalities, and Sternal cleft or supraumbilical raphe defects. This syndrome involves a large facial hemangioma that is segmental in appearance, though the IH distribution does not follow dermatomes or Blaschko's lines (skin lines believed to trace the migration of embryonic cells). The pattern of appearance appears to follow developmental units, are reproducible, and have been categorized into segments. A segment 1 distribution involves the frontotemporal forehead and upper eye with extension to the 
scalp. Segment 2 distribution involves the maxilla, segment 3 is a mandibular or "beard" distribution, and the segment 4 distribution is frontonasal, involving a strip of skin from the superior forehead along the nose to the philtrum [Figure 5] (Haggstrom et al., 2006b).

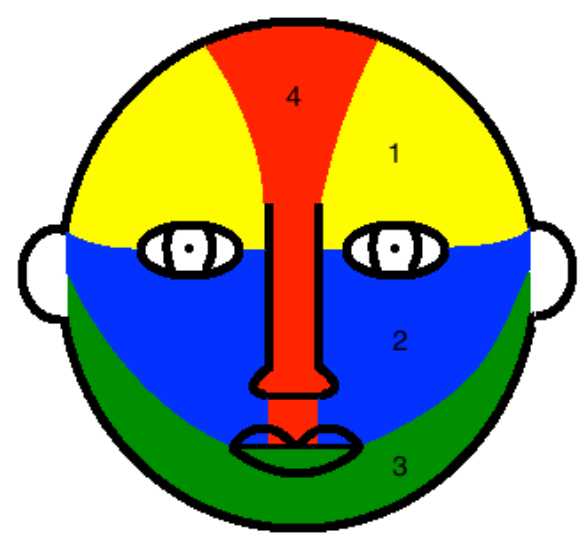

Fig. 5. Classification of facial segmental hemangioma localization into four areas based on observed distribution patterns, segments 1-4. Adapted from Haggstrom et al., 2006b.

Some of the most common and devastating of the congenital anomalies associated with PHACE syndrome are the structural brain and cerebrovascular anomalies (Drolet, et al., 2006; Metry et al., 2006; Metry et al., 2009). Structural anomalies of the brain parenchyma most commonly involve posterior fossa malformations such as Dandy-Walker syndrome, though other anomalies such as cerebral hypoplasia, microcephaly, heterotopia, and empty sella turcica have also been reported. The arterial anomalies associated with PHACE syndrome can manifest as the abnormal origin, abnormal course, hypoplasia, or absence of internal carotid or cerebral vasculature on the ipsilateral side of the facial hemangioma. Infants have also been reported to have an increased risk of vasculopathy and early stroke (Drolet et al., 2006).

Other conditions in which $\mathrm{IH}$ is associated with underlying structural defects include the well-described association of segmental lumbosacral hemangiomas with a tethered spinal cord, genitourinary anomalies, or both. Additionally, PELVIS syndrome (Perineal hemangioma-External genitalia malformations-Lipomyelomeningocele-Vesicorenal abnormalities-Imperforate anus-Skin tag) is similar to PHACES in that it too features a large hemangioma over an area with underlying structural and vascular aberrencies (Girard, Bigorre et al. 2006). In the case of PELVIS syndrome, patients present with a large segmental perineal hemangioma not localized to specific dermatomes. It is generally located from the sacral area to the thigh or pelvis, but also sometimes found to involve the vaginal wall, uterine horn, or fallopian tube. In addition, defects of the spine, genitourinary tract, and anus are found.

\section{Treatment}

First line medical treatment for problematic, proliferating IH is currently corticosteroids, though propranolol has become a favored mode of treatment recently. Intralesional 
corticosteroid injections are useful in small, well-localized tumors where the medication will be evenly distributed. Systemic treatment is indicated in cases where the IH may cause functional impairment or is life-threatening, or the large size of the hemangioma precludes local corticosteroid injection. Side effects of corticosteroids include gastrointestinal upset, weight gain, hypertension, adrenal suppression, immunosuppression, and growth delay (Maguiness \& Frieden, 2010). However, most of these effects are reversed on cessation of treatment (Boon et al., 1999). Recently, propranolol has been shown to be an effective treatment in cases where steroids have been insufficient. Many authors have reported positive results in the treatment infants with rapidly proliferating $\mathrm{IH}$, periorbital $\mathrm{IH}$, subepiglottic IH, and visceral IH (Buckmiller et al., 2009; Holmes et al., 2010; Léauté-Labrèze et al., 2008; Leboulanger et al., 2010; Li et al., 2010; Mazereeuw-Hautier et al., 2010; Sans et al., 2009; Tan et al., 2010; Truong et al., 2010). Potential side effects include bradycardia, hypotension, and hypoglycemia. In infants with PHACE syndrome, the risk of stroke is theoretically increased if propranolol is administered. The efficacy and limitations of propanolol on IHs remains to be seen.

Vincristine is another alternative treatment modality that, while possessing many known side effects when used as a chemotherapy agent, has been demonstrated as an effective drug with a good safety profile (Maguiness \& Frieden, 2010). In the past, interferon alpha ( $2 \mathrm{a}$ or $2 \mathrm{~b}$ ) has also been used in cases where corticosteroids were ineffective. However, due to the risk of spastic diplegia in children treated with interferon (Barlow et al., 1998), it is currently reserved to cases in which life-threatening IHs have not responded to other forms of treatment.

In summary, while most IHs are asymptomatic and require only monitoring and reassurance, there are subsets of $\mathrm{IHs}$ that will require aggressive intervention. Current medical treatments were discovered serendipitously and their mechanisms of action not well understood. Unless the pathogenesis and regulatory signaling mechanisms can be delineated, targeted therapy may not be possible. Despite our limited understanding, progress has been made in the basic science of IHs.

\section{Pathophysiology of IHs}

\subsection{Past studies}

Many descriptive studies have been published regarding hemangiomas. IHs have been described as a tumor of endothelial cells, but it is in fact made up of a heterogeneous group of cells including endothelial cells, myeloid cells, pericytes, and mast cells (Itinteang et al., 2011b; Tan et al., 2004; Ritter et al., 2006).

Histological studies have shown that endothelial cells in IHs are different from normal endothelial cells and vascular malformations (Mulliken \& Glowacki, 1982). In addition to expressing CD31 and von Willebrand factor (vWF), hemangioma endothelial cells (HemECs) also express type IV collagenase, vascular endothelial growth factor, and insulinlike growth factor 2 at high levels during the proliferating phase, and high levels of tissue inhibitor of metalloproteinases 1 (TIMP1) during the involuting phase (Takahashi et al., 1994). E-selectin, urokinase and basic fibroblast growth factor are expressed at high levels in both phases. HemECs also express glucose transporter 1 (GLUT1) (North et al., 2000), merosin, Lewis $Y$ antigen, and Fc gamma RII (Enjolras et al, 2007) at high levels. In particular, GLUT1 is of special interest as it is positive in $100 \%$ of $\mathrm{IH}$ endothelial cells, and not expressed in other infantile vascular tumors such as congenital hemangiomas, tufted 
angioma, kaposiform hemangioendothelioma, nor vascular malformations. GLUT1 is also expressed at high levels in the endothelial cells of barrier tissues such as placental endothelial cells and endothelial cells of the blood-brain barrier. The presence of GLUT1 is therefore useful as a diagnostic marker to confirm the histological diagnosis of IH (North et al., 2001). While these studies give valuable information to the unique appearance, history, and histological characteristics of IHs, they gave no insight into their developmental pathogenesis or regulatory mechanisms that govern the progression of IHs.

Due to the fact that endothelial cells in IHs express high levels of GLUT1, similar to placental endothelial cells, the "placental theory" of IH origin gained traction. In a study comparing the molecular gene expression profile of IHs to multiple different tissues, including brain, muscles, skin and placenta, it was found that the molecular profile of $\mathrm{IH}$ most closely resembled those of placental tissues (Barnés et al., 2005). Moreover, clinical observations of an association with $\mathrm{IH}$ incidence and exposure to chorionic villus sampling further lent credence to this theory (Bauland et al., 2010; Burton et al., 1995; Kaplan et al., 1990). Nonetheless, although these studies demonstrated an intriguing association between the placenta and $\mathrm{IH}$, they have never definitively shown a causal role for the placenta in the formation of $\mathrm{IH}$.

Studies in IHs have been further hampered by the lack of a viable animal model. Many studies have claimed to have a mouse model of hemangioma. A transgenic mouse with SV40 promoter-driven Polyomavirus Middle $\mathrm{T}$ gene demonstrated abnormal vascular proliferation with cavernous hemangioma-like structures in the skin, tongue, ear and gastric mucosa (Xu et al., 2009). The authors of this paper claimed that this was a model for IH; however, these tumors did not involute. Another xenograft model of infantile hemangioma onto nude mice did recapitulate the involuting phase, but is not an ideal laboratory model in that it has not been demonstrated that these cells can be passaged through mice and therefore requires fresh human sample tissue for each experiment (Peng et al., 2005; Tang et al., 2007). Furthermore, neither of these models recapitulate the proliferative phase of IH, and the authors of these reports did not report evidence of GLUT1 positivity.

Ritter et al (Ritter et al., 2002; 2003) was one of the first to employ microarrays in an attempt to quantify different genes that may be active in different phases of IHs. These studies showed that different genes had different expression levels in the proliferating phase versus the involuting phase. For instance, insulin-like growth factor 2 was suggested as a putative regulator of hemangioma proliferation, as its transcript levels were 10-fold higher than those in the involuting hemangiomas. However, these studies did not show causal relationships between the array data and IH behavior.

\subsection{Intrinsic theory of hemangiomas}

One important study of the basic science of IHs focused on the intrinsic vs. extrinsic origin theory, arguing that infantile hemangiomas arises from an intrinsic somatic mutation in an endothelial progenitor cell (Bischoff, 2002). By analyzing X-chromosome inactivation patterns using a polymorphism of the $X$-linked human androgen receptor gene (HUMARA), it was found that HemECs display a non-random pattern of X-chromosomal inactivation, demonstrating that each HemEC population was clonal and implicating a single progenitor cell as their origin. Additionally, non-endothelial cells isolated from hemangiomas did not display evidence of clonality, demonstrating that only endothelial cells within IHs are clonal. 
Other studies have shown that the endothelial cells isolated from IHs behave abnormally when compared to isolated endothelial cells from foreskin/commercially available dermal microvascular endothelial cells. While HemECs display many of the same markers as normal endothelial cells such as CD31, vWF, and E-selectin (in response to LPS exposure), HemECs proliferate and migrate at a faster rate in vitro in response to treatment with exogenous VEGF-A when compared with human dermal microvascular endothelial cells (HDMECs) (Boye et al., 2001). A subsequent study showed that HemECs also possess properties similar to those of immature endothelial cells, cord blood endothelial progenitor cells (cbEPCs). When exposed to the angiogenesis inhibitor endostatin, cbEPCs paradoxically exhibited increased adhesion, proliferation and migration in response to a VEGF-A gradient, while HDMECs migrated more slowly in response to endostatin exposure. Eventually, the response of cbEPCs to the same experiments shifted to mirror that of mature endothelial cells as the cells were passaged in culture. HemECs exposed to endostatin also demonstrated behavior similar to that of cbEPCs, further demonstrating their abnormal behavior when compared with normal endothelial cells (Khan et al., 2006). Taken together, these data further support the theory that an anomaly intrinsic to the IH gives rise to the lesion.

Later investigations resulted in the isolation and characterization of a cell called the hemangioma stem cell (HemSC) (Khan et al., 2008). These HemSCs were demonstrated to be highly proliferative in culture, and capable of differentiating into endothelial, adipocyte, chondrocyte, osteocyte, and neuroglial lineages. Furthermore, when mixed with Matrigel and subsequently implanted as a subcutaneous Matrigel plug into the backs of nude mice, HemSCs formed GLUT1+ endothelial cell-lined functional blood vessels during the first few weeks. Four weeks after implantation, however, the Matrigel plugs were instead found to contain adipocytes. This was the first valid published animal model of $\mathrm{IH}$, and its recapitulation of the natural history of $\mathrm{IH}$ gave further credence to the intrinsic theory of $\mathrm{IH}$ as well as evidence for the new theory of a stem cell as the cellular origin of IHs.

Some evidence also points to a possible neural crest cell origin for IHs. Waner and colleagues were the first to notice that segmental hemangiomas tend to occur at regions of embryological fusion (Waner et al., 2003). Several years later, Haggstrom and colleagues conducted a larger study, finding that certain segmental facial hemangiomas tend to respect embryological boundaries such as the maxillary and mandibular promineces, while others did not (Haggstrom et al., 2006b). Using their observations, they grouped the distribution of facial hemangiomas into four segments. Given the pattern of distribution of segmental facial hemangiomas, these groups also postulated that facial hemangiomas may have a neural crest cell origin. Expression of a marker for neural crest stem cells, p75, has also been demonstrated in proliferating IH (Itinteang et al., 2010).

\subsection{VEGF pathway}

Different pathways have been suggested as possibly being involved in the pathogenesis and development of IHs. The VEGF pathway, as one of the most important signaling molecules in normal and pathophysiological angiogenesis, has been the subject of much study. VEGFR-1 and VEGFR-2 are both expressed in IH. However, Jinnin et al demonstrated that VEGFR-2 signaling is constitutively active in cultured HemECs in the presence of VEGF-A, and that this signaling is a result of downregulated VEGFR-1 expression. VEGFR-1 is expressed at much lower levels as a result of aberrant increased interaction of a mutated 
anthrax toxin receptor-1 (ANTXR-1) with b1-integrin and VEGFR-2. The increase in this complex formation in HemECs appears to suppress NFAT-promoted transcription of VEGFR-1. As both VEGFR-1 and VEGFR-2 proteins bind to VEGF-A, and VEGFR-1 is believed to act as a negative regulator of VEGFR-2 signaling through sequestration of VEGFA, a decrease in VEGFR-1 expression would lead to constitutive VEGFR-2 signaling. This constitutive VEGFR-2 signaling in the presence of VEGF-A helps explain the aberrant overgrowth of endothelial cells in IH.

Studies involving treatment options for $\mathrm{IH}$, such as corticosteroids and propranolol, serve to further highlight the importance of the VEGF pathway in IH pathogenesis. Corticosteroids have been one of the first-line medical treatments for problematic hemangiomas. Greenberger and colleagues demonstrated that dexamethasone treatment of mice implanted with HemSCs in a Matrigel plug with led to a dose-dependent inhibition of microvessel density in those plugs. Pre-treating HemSCs with dexamethasone, or silencing VEGF-A expression in HemSCs using shRNA lentiviral particles, before implantation into mice also gave similar results. Furthermore, in vitro administration of dexamethasone to HemSCs resulted in a significant decrease in both mRNA transcript and protein expression levels of VEGF-A. The authors also showed that VEGF-A expression is present in IHs in the proliferating phase, but not in those in the involuting phase, strongly suggesting that early expression of VEGF-A by HemSCs has a crucial role in the pathogenesis of IH. (Greenberger et al., 2010b). In a subsequent study, the same authors demonstrated that treatment of HemSCs with dexamethasone suppresses the activity of nuclear factor kappa-light-chainenhancer of activated B cells (NF-kB). They also showed that direct suppression of NF- $\mathrm{B}$ activity leads to decreased VEGF-A mRNA and protein expression, suggesting that NF- $\mathrm{B}$ regulates VEGF-A expression in HemSCs and providing a plausible mechanism explaining the clinical effect of corticosteroids on IH (Greenberger et al., 2010a).

Recently, propranolol has been demonstrated to be an effective drug for the treatment of IH. In 2008, Léauté-Labrèze and colleagues reported a dramatic response to propranolol treatment in a small cohort of eleven patients with IH (Léauté-Labrèze et al., 2008). However, the molecular mechanisms behind this effect are of considerable interest. Recent work by Lamy and colleagues in HUVECs has demonstrated that treatment with propranolol inhibited proliferation, chemotactic migration, and tube formation in vitro, as well as inhibition of VEGF-A-induced tyrosine phosphorylation of VEGFR-2 (Lamy et al., 2010). While this study demonstrates that propranolol can interfere with some of the important steps involved in angiogenesis, shortcomings of this study include lack of in vivo data and the fact that none of the experiments were conducted in HemECs and limits the application of the group's conclusions to IHs. More work is needed to elucidate the mechanism of action of propranolol on the accelerated involution of $\mathrm{IH}$.

\subsection{TIE/Angiopoietin signaling}

The tyrosine kinase with immunoglobulin-like and EGF-like domains 2 (TIE2)/angiopoietin signaling pathway is also another putative regulator of IH pathogenesis. Tie1, Tie2, and angiopoietin-2 (Ang2) are strongly expressed in cultured HemECs, with low expression of Ang1. Relative to human dermal microvascular endothelial cells (HDMECs), Tie2 mRNA and protein expression are increased in HemECs, and HemECs also demonstrate a concomitant increase in cellular responsiveness to Ang1 as measured by cellular proliferation and migration. Altered regulation of Ang2 has also been observed, with Ang2 
mRNA expression in HemECs down-regulated in response to serum relative to HDMECs. Thus Tie2 and its ligands Ang1 and Ang2 likely have an important role in the pathogenesis of hemangioma (Acevedo \& Cheresh, 2008; Jinnin et al., 2008; Yu, et al., 2001).

\subsection{Notch signaling}

Recent studies have also focused on the Notch signaling pathway, a highly conserved juxtacrine signaling pathway that is involved in cell fate determination during embryogenesis. Four Notch receptor genes (Notch1-4) were found to be expressed in IHs, as well as 2 Notch ligands, Jagged-1 and Delta-like-4 (Dll-4) (Wu \& Kitajewski, 2009). Moreover, the Notch expression profile of proliferating hemangiomas is different than that of hemangiomas undergoing involution, with involuting hemangiomas demonstrating increased expression of Notch4 and Jagged-1 when compared with proliferating hemangiomas. HemSCs and HemECs also demonstrate completely different Notch expression profiles, with HemSCs expressing higher levels of Notch2 and Notch3, but lower levels of Notch1, Notch4, Jagged-1, and Dll-4 compared to HemECs (Wu et al., 2010). These data suggest a possible role for Notch signaling in the maintanence of HemSC pluripotency and differentiation into HemEC phenotype.

\subsection{Renin-angiotensin system}

Another area of focus on pathogenesis of IH is the renin-angiotensin system (Itinteang et al., 2011a). Proliferating hemangioma has been demonstrated to express both angiotensinconverting enzyme (ACE) and angiotensin receptor 2. Blast-like structures isolated from IH using an in vitro explant model expressed CD133, CD34, and VEGFR-2, as well as ACE. These blast-like structures increased in number following angiotenisin II treatment in a dose-response manner. The authors postulate that treatment of IH with propranolol exerts its effects at least partially through downregulation of renin activity of the kidney, leading to decreased conversion of angiotensinogen to angiotensin I and ultimately to decreased angiotensin II levels, thereby decreasing proliferation of IH. While interesting, whether or how the renin-angiotensin system contributes to the pathogenesis or development of IHs remain to be seen.

\subsection{Tumor endothelial cells}

It has long been known that as tumors develop and increase in size, they recruit blood vessels from their host in order to attempt to meet their increased metabolized demands by a process termed angiogenesis. The resultant vasculature is abnormal, and characterized by tortuous vessels, a disorganized sprouting, vessel leakiness, and loose associations between the vessels' endothelial cells and the basement membrane and pericytes that cover them. While an abnormal vasculature is a hallmark of solid tumors, it is only recently that there has been evidence suggesting that these blood vessels are composed of endothelial cells that are in and of themselves intrinsically abnormal as well. Endothelial cells isolated from human renal cell carcinoma have been reported to be more resistant to serum starvation and vincristineinduced apoptosis when compared to normal endothelial cells, exhibit enhanced Akt activation and decreased expression of the tumor suppressor gene PTEN, and do not undergo senescence (Bussolati et al., 2003). Murine Lewis lung carcinoma endothelial cells were characterized by a comparatively elongated cellular morphology, fewer cell-cell contacts, and increased levels of a host of endothelial cell-surface markers (Allport \& Weissleder, 2003). 
Hida and colleagues purified murine endothelial cells from human xenograft models of melanoma and liposarcoma and compared them with murine endothelial cells isolated from normal murine skin and adipose tissue. They found that endothelial cells isolated from tumors were cytogenetically different when compared to normal endothelial cells, displaying larger, heterogenous nuclei and aneuploidy that was exacerbated by passage in culture. Abnormal multiple centrosomes were also seen, and FISH analysis showed that the structural chromosomal aberrations were heterogenous, indicating that the mutations were not clonal (Hida et al., 2004). Possible mechanisms for this cytogenetic instability include the unique growth factor milieu in the tumor environment causing genetic instability; loss of tumor suppressor and checkpoint activity; uptake of human tumor oncogenes by fusion or phagocytosis of apoptotic bodies; and transdifferentiation of tumor cells into endothelial cells.

Xiong and colleages isolated endothelial cells from human hepatocellular carcinoma (HCC) and adjacent normal tissue, and reported that HCC endothelial cells demonstrate enhanced angiogenic activity including enhanced proliferation, resistance to apoptosis in the absence of serum, enhanced migration, and enhanced ability to form tubes when implanted into Matrigel in the absence of serum. These cells were also relatively resistant to chemotherapeutic drugs including adriamycin and 5-fluorouracil, and the antiangiogenic drug sorafenib. Tumor endothelial cells share many of the same characteristics of HemECs, and further research comparing the similarities and differences between the two cell types may give insight both into the origin of IHs and the unique properties of tumor endothelial cells (Xiong et al., 2009).

Interestingly, Dudley and colleagues have recently reported that tumor endothelial cells isolated from a transgenic mouse model in which the mice develop prostate adenocarcinoma at puberty demonstrate some of the features of mesenchymal stem cells. When cultured in vitro and stimulated with osteogenic medium, clonal populations of these prostate tumor endothelial cells demonstrated alkaline phosphatase activity, expressed bone-specific markers such as osteopontin and osteocalcin, and underwent mineralization. These same cells formed cartilage-like tissues when cultured in chondrogenic medium, with concomitant upregulation of cartilage-specific genes. However, these tumor endothelial cells could not be differentiated to form adipocytes, distinguishing them from normal mesenchymal stem cells and HemSCs (Dudley et al., 2008).

\section{Conclusion}

IHs remain poorly understood but may have serious clinical consequences. While many details of their pathogenesis and regulatory mechanisms are still not known, they most likely originate from a hemangioma stem cell (HemSC) that abnormally differentiate into hemangioma endothelial cells (HemEC). These HemECs are different from mature endothelial cells in that they retain features of immature endothelial progenitor cells, suggesting an abnormality in stem cell differentiation. In addition, many different signaling mechanisms have been studied as potential candidates for regulating the transition of $\mathrm{IH}$ from the proliferating to involuting phase, and from HemSC to HemEC.

Understanding the mechanisms that regulate IHs will allow directed therapy for affected infants. Moreover, IHs also serve as a model of aberrant vasculogenesis and allow for greater understanding of vascular development, including the role of the VEGF, Notch, and renin-angiotensin signaling pathways. These mechanisms may give insight into 
hematopoietic differentiation and should be investigated for their potential role in normal vasculogenesis. IHs also share many similarities with tumor endothelial cells, and further study and comparison with the unique characteristics of tumor endothelial cells could lead to new insights into tumor angiogenesis.

\section{References}

Acevedo, L. M. \& Cheresh, D. A. (2008). Suppressing NFAT increases VEGF signaling in hemangiomas. Cancer Cell, Vol. 14, No. 6, December 2009, pp. 429-430.

Allport, J.R. \& Wiessleder, R. (2003). Murine Lewis lung carcinoma-derived endothelium expresses markers of endothelial activation and requires tumor-specific extracellular matrix in vitro. Neoplasia, Vol. 5, No. 3, May-June 2003, pp. 205-217.

Amir, J., Metzker, A.; Krikler, R. \& Reisner, S.H. (1986). Strawberry hemangioma in preterm infants. Pediatric Dermatology, Vol. 3, No. 4, September 1986, 331-332.

Arneja, J. S. \& Mulliken, J. B. (2010). Resection of amblyogenic periocular hemangiomas: indications and outcomes. Plastics and Reconstructive Surgery, Vol. 125, No. 1, January 2010, pp. 274-281.

Barnés C.M.; Huang, S.; Kaipainen, A.; Sanoudou, D.; Chen, E.J.; Eichler, G.S.; Guo, Y.; Yu, Y.; Ingber, D.E.; Mulliken, J.B.; Beggs, A.H.; Folkman, J. \& Fishman, S.J. Evidence by molecular profiling for a placental origin of infantile hemangioma. Proceedings of the National Academy of Sciences of the United States of America, Vol. 102, No. 52, December 2005, pp. 19097-19102.

Barlow, C.F.; Priebe, C.J.; Mulliken, J.B.; Barnes, P.D.; MacDonald, D.; Folkman, J. \& Ezekowitz, R.A. Spastic diplegia as a complication of interferon alfa-2a treatment of hemangiomas of infancy. The Journal of Pediatrics, Vol. 132, No. 3 Pt 1, March 1998, pp. 527-530.

Bauland, C.G.; Smit, J.M.; Bartelink, L.R.; Zondervan, H.A. \& Spauwen, P.H. (2010). Hemangioma in the newborn: increased incidence after chorionic villus sampling. Prenatal Diagnosis, Vol. 30, No. 10, October 2010, pp. 913-917.

Bischoff, J. Monoclonal expansion of endothelial cells in hemangioma: an intrinsic defect with extrinsic consequences? Trends in Cardiovascular Medicine, Vol. 12, No. 5, July 2002, pp. 220-204.

Bitar, M. A.; Moukarbel, R.V. \& Zalzal, G.H. (2005). Management of congenital subglottic hemangioma: trends and success over the past 17 years. Otolaryngology-Head and Neck Surgery, Vol. 132, No. 2, February 2005, pp. 226-231.

Boon, L. M.; Burrows, P. E.; Paltiel, H.J.; Lund, D.P.; Ezekowitz, R.A.B.; Folkman, J. \& Mulliken, J.B. (1996). Hepatic vascular anomalies in infancy: a twenty-seven-year experience. The Journal of Pediatrics, Vol. 129, No. 3, September 1996, pp. 346-354.

Boon, L.M.; MacDonald, D.M. \& Mulliken, J.B. (1999). Complications of systemic corticosteroid therapy for problematic hemangioma. Plastic and Reconstructive Surgery, Vol. 104, No. 6, November 1999, pp. 1616-1623.

Bowers, R.E.; Graham, E.A. \& Tomlinson, K.M. The natural history of the strawberry nevus. Archives of Dermatology, Vol. 82, No. 5, 1960, pp. 667-680.

Boye, E.; Yu, Y.; Paranya, G.; Mulliken, J.B.; Olsen, B.R.; Bischoff, J. (2001). Clonality and altered behavior of endothelial cells from hemangiomas. The Journal of Clinical Investigation, Vol. 107, No. 6, March 2001, pp. 745-752. 
Buckmiller, L.; Dyamenahalli, U. \& Richter, G.T. Propranolol for airway hemangiomas: Case report of novel treatment. (2009). Laryngoscope, Vol. 119, No. 10, October 2009, pp. 2051-2054.

Bussolati, B.; Deambrosis, I.; Russo, S.; Deregibus, M.C. \& Camussi, G. Altered angiogenesis and survival in human tumor-derived endothelial cells. The FASEB Journal, Vol. 17, No. 9, June 2003, pp. 1159-1161.

Burrows, P.E.; Robertson, R.L.; Mulliken, J.B.; Beardsley, D.S.; Chaloupka J.C.; Ezekowitz, R.A. \& Scott, R.M. (1998). Cerebral vasculopathy and neurologic sequelae in infants with cervicofacial hemangioma: report of eight patients. Radiology, Vol. 207, No. 3, June 1998, pp. 601-607.

Burton, B.K.; Schulz, C.J.; Angle, B. \& Burd, L.I. (1995). An increased incidence of haemangiomas in infants born following chorionic villus sampling (CVS). Prenatal Diagnosis, Vol. 15, No. 3, March 1995, pp. 209-214.

Ceisler, E. \& Blei, F. (2003). Ophthalmic issues in hemangiomas of infancy. Lymphatic Research and Biology, Vol. 1, No. 4, 2003, pp. 321-330.

Ceisler, E.; Santos, L. \& Blei, F. Periocular hemangioma: what every physician should know. (2004). Pediatric Dermatology, Vol. 21, No. 1, January-February 2004, pp. 1-9.

Chamlin, S. L.; Haggstrom, A. N.; Drolet, B.A.; Baselga, E.; Frieden, I.J.; Garzon, M.C.; Horii, K.A.; Lucky, A.W.; Metry, D.W.; Newell, B.; Nopper, A.J. \& Mancini, A.J. (2007). Multicenter prospective study of ulcerated hemangiomas. The Journal of Pediatrics, Vol. 151, No. 6, December 2007, pp. 684-689.

Christison-Lagay, E.R.; Burrows, P.E.; Alomari, A; Dubois, J.; Kozakewich, H.P.; Lane, T.S.; Paltiel, H.J.; Klement, G.; Mulliken, J.B.\& Fishman, S.J. (2007). Hepatic hemangiomas: Subtype classification and development of a clinical practice algorithm and registry. Journal of Pediatric Surgery, Vol. 42, No. 1, January 2007, pp. 62-67.

Drolet, B.A.; Dohil, M.; Golomb, M.R.; Wells, R.; Murowski, L.; Tamburro, J.; Sty, J. \& Friedlander, S.F. (2006). Early stroke and cerebral vasculopathy in children with facial hemangiomas and PHACE association. Pediatrics, Vol. 117, No. 3, March 2006, pp. 959-964.

Dudley, A.C.; Khan, Z.A.; Shih, S.C.; Kang, S.Y.; Zwaans, B.M.M.; Bischoff, J. \& Klagsbrun, M. (2008). Calcification of multipotent prostate tumor endothelium. Cancer Cell, Vol. 14, No. 3, September 2008, pp. 201-211.

Enjolras, O.; Wassef, M. \& Chapot, R. (May 2007). Color Atlast of Vascular Tumors and Vascular Malformations, Cambridge University Press, ISBN 978-0-521-84851-0, New York, NY.

Frieden, I. J.; Haggstrom, A. N.; Drolet, B.A.; Mancini, A.J.; Friedlander, S.F.; Boon, L.; Chamlin, S.L.; Baselga E.; Garzon, M.C.; Nopper A.J.; Siegel, D.H.; Mathes, E.W.; Goddard, D.S.; Bischoff, J.; North, P.E. \& Esterly, N.B. (2005). Infantile hemangiomas: current knowledge, future directions. Proceedings of a research workshop on infantile hemangiomas, April 7-9, 2005, Bethesda, Maryland, USA. Pediatric Dermatology, Vol. 22, No. 5, September-October 2005, pp. 383-406.

Frieden, I.J.; Reese, V. \& Cohen, D. (1996). PHACE syndrome. The association of posterior fossa brain malformations, hemangiomas, arterial anomalies, coarctation of the aorta and cardiac defects, and eye abnormalities. Archives of Dermatology, Vol. 132, No. 3, March 1996, pp. 307-311. 
Greenberger, S.; Adini, I.; Boscolo, E.; Mulliken, J.B.; Bischoff, J. (2010). Targeting NF-кB in infantile hemangioma-derived stem cells reduces VEGF-A expression. Angiogenesis, Vol. 13, No. 4, December 2010, pp. 327-335.

Greenberger, S.; Boscolo, E.; Adini, I.; Mulliken, J.B. \& Bischoff, J. (2010). Corticosteroid suppression of VEGF-A in infantile hemangioma-derived stem cells. The New England Journal of Medicine, Vol. 362, No. 11, March 2010, pp. 1005-13.

Girard, C.; Bigorre, M.; Guillot, B. \& Bessis, D. (2006). PELVIS Syndrome. Archives of Dermatology, Vol. 142, No. 7, July 2006, pp. 884-888.

Haggstrom, A. N.; Drolet, B. A.; Baselga, E.; Chamlin, S.L.; Garzon, M.C.; Horii, K.A.; Lucky, A.W.; Mancini, A.J.; Metry, D.W.; Newell, B.; Nopper, A.J. \& Frieden, I.J. (2006). Prospective study of infantile hemangiomas: clinical characteristics predicting complications and treatment. Pediatrics, Vol. 118, No. 3, September 2006, pp. 882887.

Haggstrom, A. N.; Lammer, E.J.; Schneider, R.A.; Marcucio, R. \& Frieden, I.J. (2006). Patterns of infantile hemangiomas: new clues to hemangioma pathogenesis and embryonic facial development. Pediatrics, Vol. 117, No. 3, March 2006, pp. 698-703.

Hida, K.; Hida, Y.; Amin, D.N.; Flint, A.F.; Panigrahy, D.; Morton, C.C. \& Klagsbrun, M. (2004). Tumor-associated endothelial cells with cytogenetic abnormalities. Cancer Research, Vol. 64, No. 22, November 2004, pp. 8249-8255.

Holmdahl, K. (1955). Cutaneous hemangiomas in premature and mature infants. Acta Paediatrica, Vol. 44, No. 4, July 1955, pp. 370-379.

Holmes, W.J.M.; Mishra, A.; Gorst, C. \& Liew, S.H. (2010). Propranolol as first-line treatment for rapidly proliferating infantile hemangiomas. Journal of Plastic, Reconstructive, $\mathcal{E}$ Aesthetic Surgery, Vol. 64, No. 4, April 2011, pp. 445-451.

Itinteang, T.; Brasch, H.D.; Tan, S.T. \& Day, D.J. (2011). Expression of components of the renin-angiotensin system in proliferating infantile hemangioma may account for the propranolol-induced accelerated involution. Journal of Plastic, Reconstructive, $\mathcal{E}$ Aesthetic Surgery, Vol. 64, No. 6, June 2011, pp. 759-765.

Itinteang, T.; Tan, S.T.; Brasch, H. \& Day, D.J. (2010). Primitive mesodermal cells with a neural crest stem cell phenotype predominate proliferating infantile haemangioma. Journal of Clinical Pathology, Vol. 63, No. 9, September 2010, pp. 771-776.

Itinteang, T.; Vishvanath, A.; Day, D.J. \& Tan, S.T. (2011). Mesenchymal stem cells in infantile haemangioma. Journal of Clinical Pathology, Vol. 64, No. 3, March 2011, pp. 232-236.

Jinnin, M.; Medici, D.; Park, L.; Limaye, N.; Liu, Y.; Boscolo, E.; Bischoff, J.; Vikkula, M.; Boye, E. \& Olsen, B.R. (2008). Suppressed NFAT-dependent VEGFR1 expression and constitutive VEGFR2 signaling in infantile hemangioma. Nature Medicine, Vol. 14, No. 11, November 2008, pp. 1236-1246.

Kaplan, P.; Normandin, J. Jr.; Wilson, G.N.; Plauchu, H.; Lippman, A. \& Vekemans, M. (1990). Malformations and minor anomalies in children whose mothers had prenatal diagnosis: comparison between CVS and amniocentesis. American Journal of Medical Genetics, Vol. 37, No. 3, pp. 366-370.

Khan, Z.A.; Boscolo, E.; Picard, A.; Psutka, S.; Melero-Martin, J.M.; Bartch, T.C.; Mulliken, J.B.; Bischoff, J. (2008). Multipotential stem cells recapitulate human infantile hemangioma in immunodeficient mice. The Journal of Clinical Investigation, Vol. 118, No. 7, July 2008, pp. 2592-2599. 
Khan, Z.A.; Melero-Martin, J.M.; Wu, X.; Paruchuri, S.; Boscolo, E.; Mulliken, J.M. \& Bischoff, J. (2006). Endothelial progenitor cells from infantile hemangioma and umbilical cord blood display unique cellular responses to endostatin. Blood, Vol. 108, No. 3, August 2006, pp. 915-921.

Lamy, S.; Lachambre, M.P.; Lord-Dufour, S. \& Béliveau, R. (2010). Propranolol suppresses angiogenesis in vitro: inhibition of proliferation, migration, and differentiation of endothelial cells. Vascular Pharmacology, Vol. 53, No. 5-6, November-December 2010, pp. 200-8.

Léauté-Labrèze, C.; Dumas de la Roque, E.; Hubiche, T.; Boralevi, F.; Thambo, J.B.; Taïeb, A. (2008). Propranolol for sever hemangiomas of infancy. The New England Journal of Medicine, Vol. 358, No. 24, June 2008, pp. 2649-2651.

Leboulanger, N.; Fayoux, P.; Teissier, N.; Cox, A.; Van Den Abbeele, T.; Carrabin, L.; Couloigner, V.; Nicollas, R.; Triglia, J.M.; Ayari, S.; Froehlich, P.; Lescanne, E.; Marianowski, R.; Mom, T.; Mondain, M.; Marie, J.P.; Roger, G.; Garabédian, E.N. \& Denoyelle, F. Propranolol in the therapeutic strategy of infantile laryngotracheal hemangioma: a preliminary retrospective study of French experience. (2010). The International Journal of Pediatric Otorhinolaryngology, Vol. 74, No. 11, November 2010, pp. 1254-1257.

Li, Y.C.; McCahon, E.; Rowe, N.A.; Martin, P.A.; Wilcsek, G.A. \& Martin, F.J. (2010). Successful treatment of infantile hemangiomas of the orbit with propranolol. Clinical \& Experimental Ophthalmology, Vol. 38, No. 6, August 2010, pp. 554-559.

Maguiness, S.M., \& Frieden, I.J. (2010). Current management of infantile hemangiomas. Seminars in Cutaneous Medicine and Surgery, Vol. 29, No. 2, June 2010, pp. 106-114.

Mazereeuw-Hautier, J.; Hoeger, P.H.; Benlahrech, S.; Ammour, A.; Broue, P.; Vial, J.; Ohanessian, G.; Léauté-Labrèze, C.; Labenne, M.; Vabres, P.; Rössler, J. \& and Bodemer, C. (2010). Efficacy of Propranolol in Hepatic Infantile Hemangiomas with Diffuse Neonatal Hemangiomatosis. The Journal of Pediatrics, Vol. 157, No. 2, pp. 340-342.

Metry, D.W.; Haggstrom, A.N.; Drolet, B.A.; Baselga, E.; Chamlin, S.; Garzon, M.; Horil, K.; Lucky, A.; Mancini, A.J.; Newell, B.; Nopper, A.; Heyer, G. \& Frieden, I.J. (2006). A prospective study of PHACE syndrome in infantile hemangiomas: demographic features, clinical findings, and complications. American Journal of Medical Genetics, Vol. 140, No. 9, May 2006, pp. 975-986.

Metry, D.; Heyer, G.; Hess, C.; Garzon, M.; Haggstrom, A.; Frommelt, P.; Adams, D.; Siegel, D.; Hall, K.; Powell, J.; Frieden, I. \& Drolet, B. (2009). Consensus Statement on Diagnostic Criteria for PHACE Syndrome. Pediatrics, Vol. 124, No. 5, November 2009, pp. 1447-1456.

Mulliken, J.M.; Fishman, S.J. \& Burrows, P.E. (2000). Vascular anomalies. Current Problems in Surgery, Vol. 37, No. 8, August 2000, pp. 517-584.

Mulliken, J.M. \& Glowacki, J. (1982). Hemangiomas and vascular malformations in infants and children: a classifcation based on endothelial characteristics. Plastic and Reconstructive Surgery, Vol. 69, No. 3, March 1982, pp. 412-422.

North, P.E.; Waner, M.; Mizeracki, A.; Mrak, R.E.; Nicholas, R.; Kincannon, J.; Suen, J.Y. \& Mihm, M.C. Jr. (2001). A unique microvascular phenotype shared by juvenile hemangiomas and human placenta. Archives of Dermatology, Vol. 137, No. 5, May 2001, pp. 559-70. 
North, P.E.; Waner, M.; Mizeracki, A. \& Mihm, M.C. Jr. GLUT1: a newly discovered immunohistochemical marker for juvenile hemangiomas. Human Pathology, Vol. 31, No. 1, January 2000, pp. 11-22.

Orlow, S.J.; Isdoff, M.S. \& Blei, F. (1997). Increased risk of symptomatic hemangiomas of the airway in association with cutaneous hemangiomas in a "beard" distribution. The Journal of Pediatrics, Vol. 131, No. 4, October 1997, pp. 643-646.

Peng, Q.; Liu, W.; Tang, Y. \& Yu, S. (2005). The establishment of the hemangioma model in a nude mouse. Journal of Pediatric Surgery, Vol. 40, No. 7, July 2005, pp. 1167-1172.

Rahbar, R.; Nicollas, R.; Roger, G.; Triglia, J.M.; Garabedian, E.N.; McGill, T.J. \& Healy, G.B. (2004). The biology and management of subglottic hemangioma: past, present, future. The Laryngoscope, Vol. 114, No. 11, November 2004, pp. 1180-1891.

Ritter, M.R.; Dorrell, M.I.; Edmonds, J.; Friedlander, S.F. \& Friedlander, M. (2002). Insulinlike growth factor 2 and potential regulators of hemangioma growth and involution identified by large-scale expression analysis. Proceedings of the National Academy of Sciences of the United States of America, Vol. 99, No. 11, May 2002, pp. 7455-7460.

Ritter, M.R.; Moreno, S.K.; Dorrell, M.I.; Rubens, J.; Ney, J.; Friedlander, D.F.; Bergman, J.; Cunningham, B.B.; Eichenfield, L.; Reinisch, J.; Cohen, S.; Veccione, T.; Holmes, R.; Friedlander, S.F. \& Friedlander, M. (2003). Identifying potential regulators of infantile hemangioma progression through large-scale expression analysis: a possible role for the immune system and indoleamine 2,3 dioxygenase (IDO) during involution. Lymphatic Research and Biology, Vol. 1, No. 4, 2003, pp. 291-299.

Ritter, M.R.; Reinisch, J.; Friedlander, S.F. \& Friedlander, M. (2006). Myeloid cells in infantile hemangioma. The American Journal of Pathology, Vol. 168, No. 2, February 2006, pp. 621-8.

Saetti, R.; Silvestrini, M.; Cutrone, C. \& Name, S. (2008). Treatment of congenital subglottic hemangiomas: Our experience compared with reports in the literature. Archives of Otolaryngology - Head and Neck Surgery, Vol. 134, No. 8, August 2008, pp.848-851.

Sans, V.; de la Roque, E.D.; Berge, J.; Grenier, N.; Boralevi, F.; Mazereeuw-Hautier, J.; Lipsker, D.; Dupuis, E.; Ezzedine, K.; Vergnes, P.; Taïeb, A. \& Léauté-Labrèze, C. (2009). Propranolol for severe infantile hemangiomas: follow-up report. Pediatrics, Vol. 124, No. 3, September 2009, pp. e423-431.

Schwartz, S. R.; Blei, F.; Ceisler, E.; Steel, M.; Furlan, L. \& Kodsi, S. (2006). Risk factors for amblyopia in children with capillary hemangiomas of the eyelids and orbit. Journal of AAPOS, Vol. 10, No. 3, June 2006, pp. 262-268.

Takahashi, K.; Mulliken, J.B., Kozakewich, H.P.; Rogers, R.A.; Folkman, J. \& Ezekowitz, R.A. (1994). Cellular markers that distinguish the phases of hemangioma during infancy and childhood. The Journal of Clinical Investigation, Vol. 93, No. 6, June 1994, pp. 2357-2364.

Tan, S.T.; Itinteang, T. \& Leadbitter, P. (2010). Low-dose propranolol for infantile haemangioma. Journal of Plastic, Reconstructive, \& Aesthetic Surgery, Vol. 64, No. 3, March 2011, pp. 292-299.

Tan, S.T.; Wallis, R.A.; He, Y. \& Davis, P.F. (2004). Mast cells and hemangioma. Plastic and Reconstructive Surgery, Vol. 113, No. 3, March 2004, pp. 999-1011.

Tang, Y.; Liu, W.; Yu, S.; Wang, Y.; Peng, Q.; Xiong, Z.; Wang, Y. \& Wei, T. (2007) A novel in vivo model of human hemangioma: xenograft of human hemangioma tissue on 
nude mice. Plastic and Reconstructive Surgery, Vol. 120, No. 4, September 2007, pp. 869-878.

Truong, M.T.; Perkins, J.A.; Messner, A.H. \& Chang, K.W. (2010). Propranolol for the treatment of airway hemangiomas: a case series and treatment algorithm. International Journal of Pediatric Otorhinolaryngology, Vol. 74, No. 9, September 2010, pp. 1043-1048.

Waner, M.; North, P.E.; Scherer, K.A.; Frieden, I.J.; Waner, A. \& Mihm, M.C. Jr. (2003). The nonrandom distribution of facial hemangiomas. Archives of Dermatology, Vol. 139, No. 7, July 2003, pp. 869-875.

Wu, J.K.; Adepoju, O.; De Silva, D.; Baribault, K.; Boscolo, E.; Bischoff, J. \& Kitajewski, J. (2010). A switch in notch gene expression parallels stem cell to endothelial cell transition in infantile hemangioma. Angiogenesis, Vol. 13, No. 1, March 2010, pp. 1523.

Wu, J.K. \& Kitajewski, J.K. (2009). A potential role for notch signaling in the pathogenesis and regulation of hemangiomas. The Journal of Craniofacial Surgery, Vol. 20, Suppl 1, March 2009, pp. 698-702.

Xiong, Y.Q.; Sun, H.C.; Zhang, W.; Zhu, X.D.; Zhuang, P.Y.; Zhang, J.B.; Wang, L.; Wu, W.Z.; Qin, L.X. \&Tang, Z.Y. (2009). Human hepatocellular carcinoma tumor-derived endothelial cells manifest increased angiogenesis capability and drug resistance compared with normal endothelial cells. Clinical Cancer Research, Vol. 15, No. 15, August 2009, pp. 4838-4846.

Xu, Q.; Chen, W.; Wang, Z.; Zheng, J. \& Zhang, Z. (2009). Mice transgenic with SV40-latepromoter-driven polyomavirus middle $T$ oncogene exclusively develop hemangiomas. Transgenic Research, Vol. 18, No. 3, June 2009, pp. 399-406.

Yu Y.; Varughese, J.; Brown, L.F.; Mulliken, J.B. \& Bischoff, J. Increased Tie2 expression, enhanced response to angiopoietin-1, and dysregulated angiopoietin-2 expression in hemangioma-derived endothelial cells. The American Journal of Pathology, Vol. 159, No. 6, December 2001, pp. 2271-2280. 


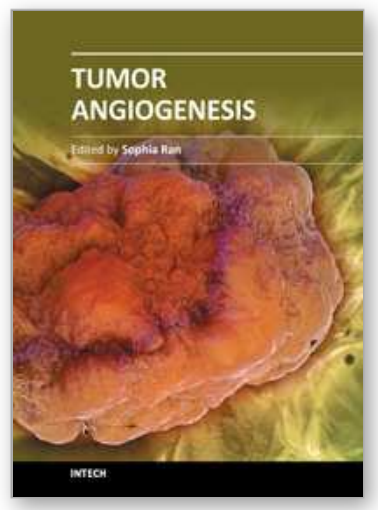

\author{
Tumor Angiogenesis \\ Edited by Dr. Sophia Ran
}

ISBN 978-953-51-0009-6

Hard cover, 296 pages

Publisher InTech

Published online 17, February, 2012

Published in print edition February, 2012

Tumor angiogenesis is the main process responsible for the formation of new blood vessels that promote tumor growth and metastasis. This process is driven by potent pro-angiogenic factors that are predominant in the tumor environment and are produced by both malignant cells and the host cells recruited to the tumor site. Tumor environment is characterized by the imbalance between pro-angiogenic and anti-angiogenic factors, which drives the construction of numerous but structurally defective vessels. These poorly perfused and abnormal vessels significantly contribute to the tumor pathology not only by supporting the expansion of the tumor mass but also by promoting chronic inflammation, enhancing thrombosis, impeding drug delivery, and disseminating tumor cells. These problems associated with tumor vasculature continue to attract great attention of scientists and clinicians interested in advancing the understanding of tumor biology and development of new drugs. This book complies a series of reviews that cover a broad spectrum of current topics related to the pathology of tumor blood vessels including mechanisms inducing new vessels, identification of new targets for inhibition of tumor angiogenesis, and potential clinical use of known and novel anti-angiogenic therapies. The book provides an update on tumor angiogenesis that could be useful for oncologists, cancer researchers and biologists with interests in vascular and endothelial cell behavior in the context of cancer.

\title{
How to reference
}

In order to correctly reference this scholarly work, feel free to copy and paste the following:

Alvin Wong and June K. Wu (2012). Infantile Hemangiomas: A Disease Model in the Study of Vascular Development, Aberrant Vasculogenesis and Angiogenesis, Tumor Angiogenesis, Dr. Sophia Ran (Ed.), ISBN: 978-953-51-0009-6, InTech, Available from: http://www.intechopen.com/books/tumor-angiogenesis/infantilehemangiomas-a-disease-model-in-the-study-of-vascular-development-aberrant-vasculogenesis-a

\section{INTECH}

open science | open minds

\section{InTech Europe}

University Campus STeP Ri

Slavka Krautzeka 83/A

51000 Rijeka, Croatia

Phone: +385 (51) 770447

Fax: +385 (51) 686166

\section{InTech China}

Unit 405, Office Block, Hotel Equatorial Shanghai

No.65, Yan An Road (West), Shanghai, 200040, China 中国上海市延安西路65号上海国际贵都大饭店办公楼 405 单元

Phone: +86-21-62489820

Fax: +86-21-62489821 
www.intechopen.com 
(C) 2012 The Author(s). Licensee IntechOpen. This is an open access article distributed under the terms of the Creative Commons Attribution 3.0 License, which permits unrestricted use, distribution, and reproduction in any medium, provided the original work is properly cited. 